\title{
Effects of Glutamate and $\gamma$-Aminobutyric Acid on Spontaneously Active Intraocular Spinal Cord Graft Neurons
}

\author{
J.G. Broton, R.P. Yezierski, and Å. Seiger \\ Department of Neurological Surgery, School of Medicine \\ University of Miami, Miami, FL 33136, USA
}

\begin{abstract}
Pieces of fetal rat lumbar spinal cord were transplanted into the anterior eye chamber of adult rat hosts. At least seven months later, extracellular single-unit recordings of spontaneously active graft neurons were made prior to and during the superfusion of either glutamate or $\boldsymbol{\gamma}$-aminobutyric acid (GABA). Superfusion of glutamate produced an increase (five cells), decrease (three cells), or had no effect (two cells) on the firing rate of neurons tested. Superfusion of GABA decreased the firing rate of all twelve neurons tested, while superfusion of the GABA receptor antagonist bicuculline increased the firing
\end{abstract}

Reprint address:

Dr. R.P. Yezierski

Dept. of Neurological Surgery

1600 N.W. 10th Ave. (R48)

Miami, FL 33136

USA

VOL. 2, NO. 2, 1991 rates of all eight neurons tested. The latency and magnitude of the responses to glutamate and GABA were not related to depth of the recording electrode below the graft surface. Together, these data suggest that the intraocular spinal cord graft is suitable for the in vivo study of GABA and glutamate neuropharmacology.

\section{KEY WORDS}

Intraocular graft, glutamate, $\boldsymbol{\gamma}$-aminobutyric acid, bicuculline, superfusion, spinal cord, rat

\section{INTRODUCTION}

Fetal rat spinal cord tissue will develop in the anterior eye chamber of adult rat hosts $/ 15,29,39 /$. The grafts are quickly vascularized by the host iris, increase in 
size for the first six weeks in the eye, and maintain their general appearance for the life of the host /15,34/. Using this in vivo preparation, the growth $/ 15,19 /$, organotypical development $/ 16,17 /$ and cellular organization $/ 6,15 /$ of isolated spinal cord neurons have been studied.

Dissociated fetal spinal cord tissue cultures are routinely used to characterize neurotransmitter action in vitro $/ 36 /$. There are, however, advantages to be gained by using intraocular grafts for such studies. First, the tissue is not dissociated prior to transplantation, resulting in the preservation of some neuronal organization. We have shown that neurons in intraocular spinal cord grafts are in many ways similar in appearance and organization to neurons in the intact spinal cord $/ 6 /$. This contrasts with cultured spinal cord neurons, which develop neurites /32/ that do not resemble dendrites and axons in situ. Second, intraocular spinal cord grafts are nourished by the host's blood supply via a dense capillary network /6/ originating from the ground plexus of the host iris $/ 15 /$. This is in contrast to the artificial medium which is fed to cultured spinal cord neurons or slice preparations. Third, intraocular grafts provide a means to study transplanted tissue for long time periods after manipulations of blood constituents or anterior eye chamber fluid. A previous study has described changes in the growth of spinal cord grafts after intravenous administration of thyrotropin releasing hormone to the adult hosts $/ 19 /$. Also, colchicine has been injected into the anterior eye chamber several weeks after tissue transplantation in order to visualize neuropeptides in graft cell bodies $/ 16 /$. These studies indicate that intraocular grafts provide a flexible model system to study neurotransmitter actions of developing tissue transplanted to the eye from different regions of the central nervous system, including the spinal cord. Previous electrophysiological studies have shown that spinal cord graft neurons respond to norepinephrine $/ 14$ / and serotonin /18/. Two other putative neurotransmitter substances present in the spinal cord are glutamate and GABA. The present study was undertaken to evaluate the action of these substances on neuronal activity in intraocular spinal cord grafts.

Glutamate is an excitatory amino acid which is present both in the dorsal and ventral gray matter of the spinal cord $/ 5,12 /$. Glutamate binding sites have been found in the spinal dorsal horn $/ 13 /$, implicating glutamate in the transmission of afferent input to the spinal cord. Glutamate iontophoresis near spinal neurons results in increased neuronal activity $/ 8,10,37 /$. In the in vitro spinal cord slice preparation, glutamate superfusion results in membrane depolarization /22/ and an increase in neuronal excitability $/ 33 /$ similar to that produced by stimulation of the attached dorsal root ganglion. It is thought that this effect is mediated by glutamate released from primary afferent fibers $/ 33 /$, since glutamate is found in dorsal root ganglion cells /11/. Additionally, glutamate-like immunoreactivity has been observed in spinal neurons /28/; and destruction of second-order dorsal horn neurons by anoxia results in a reduction of glutamate in the dorsal horn $/ 9 /$. These findings suggest that glutamate may also be used by spinal cord interneurons. Glutamate-like immunoreactivity has been found in intraocular spinal cord graft neurons (Miller, 1989, personal communication) and glutamate has been used to facilitate neuronal activity in electrophysiological studies of intraocular spinal cord grafts $/ 14,18,29 /$. However, the effects of glutamate superfusion on individual spinal cord graft neurons have not been studied previously.

Another amino acid found in the spinal cord is GABA $/ 12,25 /$. The GABA synthesizing enzyme glutamic acid decarboxylase (GAD) is localized in nerve terminals /2,27/ and, after colchicine pretreatment, in cell bodies $/ 3 /$ throughout the dorsal and ventral gray matter. The presence of GABA in intraocular spinal cord grafts has not been established. In the spinal cord, GABA has been implicated in postsynaptic inhibition $/ 8 /$ as well as primary afferent depolarization after primary afferent stimulation $/ 24 /$. The synaptic mechanism of GABA function has been studied extensively in in vitro studies of cultured spinal cord neurons $/ 4,35 /$. The effect of GABA on transplanted spinal neurons has not been determined. In the present study, GABA and the GABA receptor antagonist bicuculline were administered while recording from individual, spontaneously active spinal cord graft neurons. Some of the results have been reported previously in abstract form $/ 7 /$. 


\section{METHODS}

\section{Intraocular Grafting}

The intraocular grafts used in this study were transplanted at the same time as the grafts described in a previous report $/ 6 /$. The grafting procedure has been described in detail $/ 30 /$. Briefly, spinal cord tissue was obtained from E14-E15 rat embryos. Timed-pregnant rats were anesthetized with ether and sacrificed by neck dislocation, and fetuses were removed via a midline incision. Under a dissection microscope, fetal spinal cord tissue was isolated and bathed in Earle's balanced salt solution (EBSS). Each graft contained a hemisection of one lumbar spinal cord segment freed from surrounding meningeal tissue. Grafts were placed bilaterally into the anterior eye chamber of etheranesthetized adult rats through a small incision in the host cornea. The grafts were viewed through the cornea and measured several times during their first three months in oculo. The growth curves of these grafts were similar to those reported previously / $15 /$. Only large, well vascularized grafts were used for recording experiments. Recordings were made 7-9 months after transplantation. Since consistent effects were obtained with each drug tested, it was concluded that no significant changes related to the pharmacology of GABA-ergic or glutaminergic systems occurred during this time interval.

\section{Electrophysiological Recordings}

Host rats were anesthetized with urethane $(1.25 \mathrm{~g} / \mathrm{kg})$ and tracheotomized. Body temperature and percent expired $\mathrm{CO}_{2}$ were continuously monitored and maintained within physiological limits. Rats were placed in a stereotaxic apparatus and the cornea was slit to expose the graft. A schematic drawing of the recording and drug superfusion setup is shown in Figure 1. A small plastic cylinder (8 mm I.D.) similar to that described previously $/ 20 /$ was positioned

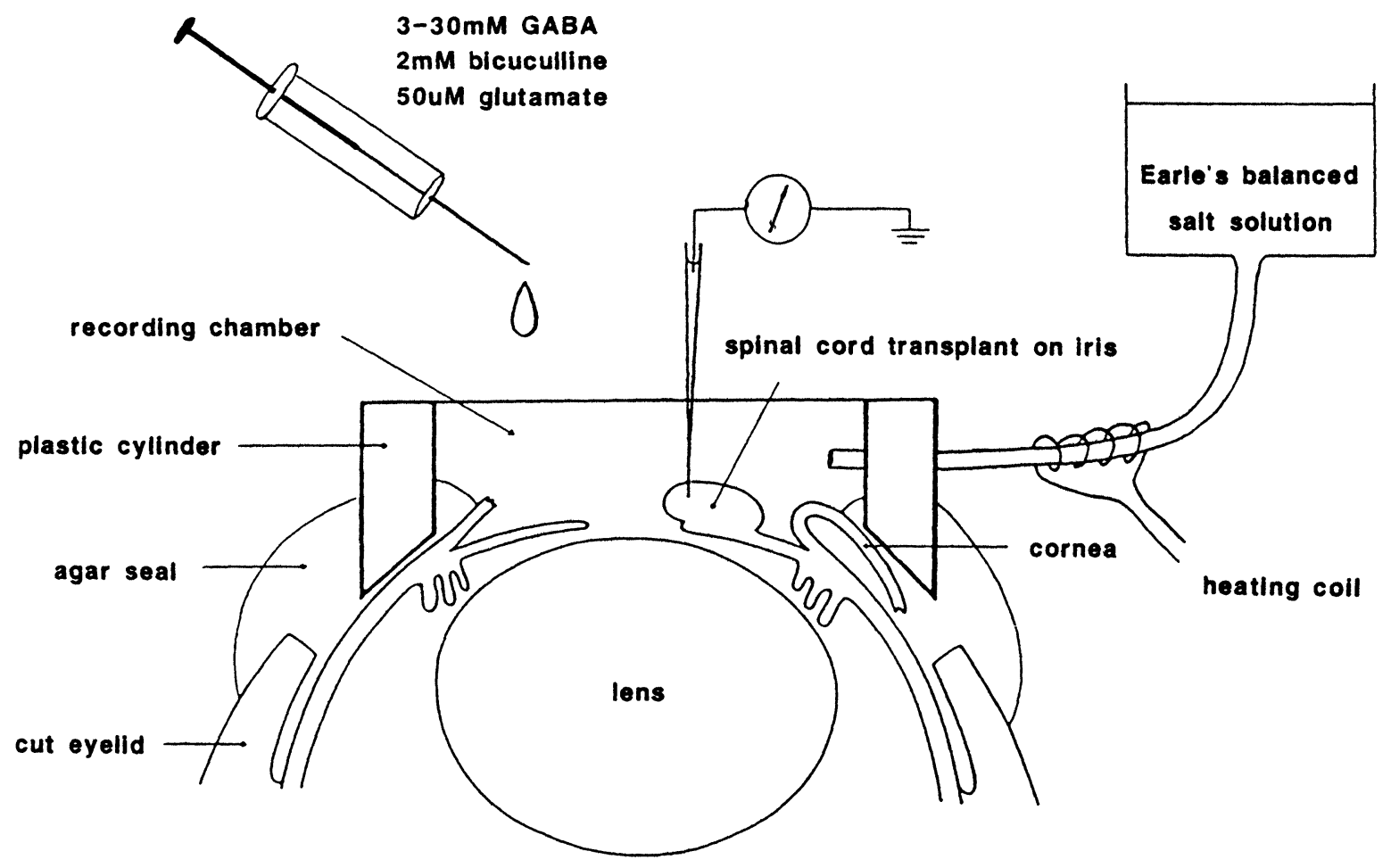

Fig. 1: Schematic drawing of the intraocular graft recording and superfusion setup used in the rat (see text). 
around the eye. The junction between the eyeball and the cylinder was sealed with agar. The recording chamber was infused with EBSS at a rate of $120 \mu \mathrm{l} /$ $\min$. Given the infusion rate and the volume of the recording chamber (approximately $200 \mu \mathrm{l}$ ), the infusion chamber solution was renewed approximately every two minutes. The EBSS was warmed by a heating coil attached to a thermistor-controlled feedback circuit which maintained the chamber solution at $36^{\circ} \mathrm{C}$. Single-unit recordings were made using etched carbon filament microelectrodes $/ 1 /$. Signals were amplified using conventional techniques, and activity from single neurons was isolated with a window discriminator. Discriminator output pulses were used to provide audio feedback of a cell's discharge and to trigger a laboratory computer (Medical Systems) that was used to construct peristimulus time histograms.

\section{Drug Superfusion}

Superfused drugs included L-glutamic acid (Sigma), GABA (Sigma), and bicuculline methiodide (Research Biochemicals Inc.). Each drug was dissolved in EBSS and delivered at room temperature via a Hamilton $50 \mu 1$ syringe as a $10 \mu \mathrm{l}$ drop into the recording chamber. The concentration of drug available to individual graft neurons can only be estimated. Given the approximate volume of EBSS in the recording chamber $(200 \mu \mathrm{l})$, the concentration of drug at the graft surface was approximately $1 / 20$ that in the stock solution. In the text and figures below, the drug concentration in the $10 \mu \mathrm{l}$ drop is stated. While this might not reflect the drug concentration available at the surface of the graft, it does accurately describe the method of superfusion used in this study.

Neurons tested for the effects of drug superfusion had regular spontaneous firing rates when calculated over a 30-90 sec period (see Results below). A drug was considered effective if the average firing rate of a neuron (calculated from a $30 \mathrm{sec}$ pre-drug control period) increased or decreased by more than $20 \%$ during a 30,60 , or $90 \mathrm{sec}$ period after drug superfusion. The onset of the drug effect was determined by the bin-by-bin analysis of peristimulus time histograms. The magnitude of drug effects was calculated by comparing the neuronal activity during the $30 \mathrm{sec}$ control period to that of the $30 \mathrm{sec}$ period after the onset of each drug effect. Any changes in firing rate of the recorded neuron after drug superfusion are presumed to be the result of drug action on the entire population of graft neurons rather than a direct effect on the neuron under study.

\section{RESULTS}

The results described below are based on single-unit recordings of spinal cord graft neurons from twelve intraocular grafts. Three grafts were used to study the patterns of spontaneous activity of these neurons; no drugs were superfused onto these grafts. Four different grafts were used to determine the minimum concentrations of glutamate, GABA, and bicuculline needed to produce effects on graft neurons. Finally, five grafts were used to study in detail the effects of drug superfusions on spontaneous activity. An average of four neurons was recorded from each of the twelve grafts used in this study.

\section{Spontaneous Activity}

All neurons in this study were identified by the presence of spontaneous activity. This activity was easily distinguishable from that of neurons that were irritated or killed by the advancing electrode, in that the former displayed action potentials which slowly increased in amplitude as the microelectrode was lowered into the graft, then remained at a relatively constant amplitude during the time they were studied.

The spontaneous activity of 14 neurons was studied in detail to determine the general discharge patterns of spinal cord graft neurons. The mean firing rate of each neuron evaluated over 30,60 , or $90 \mathrm{sec}$ intervals was found to be relatively constant. However, the pattern of discharge during these intervals fell into three distinct categories. Seven of the 14 neurons had very regular rates of activity which varied by $3 \mathrm{~Hz}$ or less from their mean firing rate of 3-16 Hz. Neurons with this pattern of activity are illustrated in Figures 2 and 5. These neurons were classified as Type A neurons. Five neurons displayed firing patterns that were more variable. These neurons, classified as Type B neurons, had firing rates during a one-second sampling period that could vary as much as $10 \mathrm{~Hz}$ from their average firing rate. Two Type $B$ neurons 
A

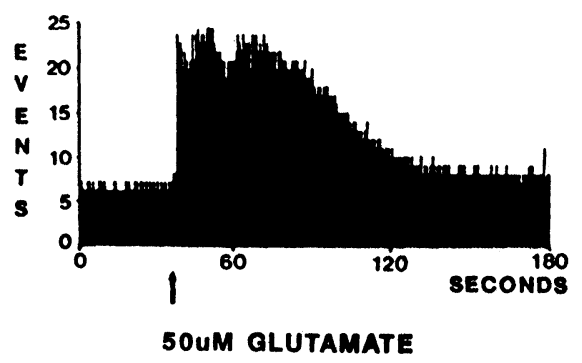

B

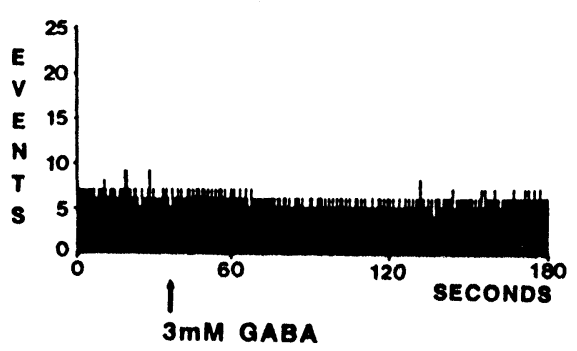

C

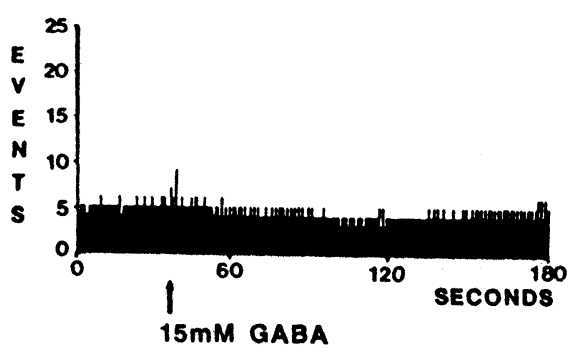

D

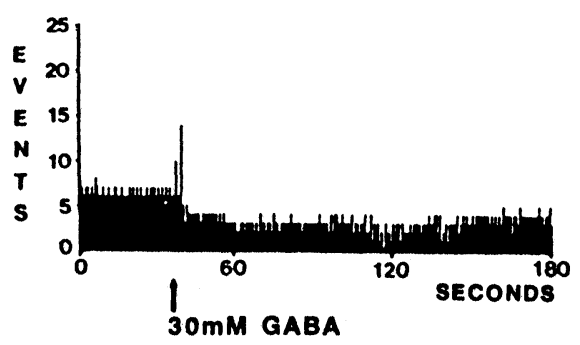

Fig. 2: Effects of glutamate and GABA superfusions (arrows) on the spontaneous firing rate of an intraocular graft neuron. For this Type A neuron (see text), $50 \mu \mathrm{M}$ glutamate (A) increased the firing rate $322 \%$ over the pre-drug level. Subsequently, GABA was superfused at (B) $3 \mathrm{mM}$, (C) $15 \mathrm{mM}$, and (D) $30 \mathrm{mM}$ concentrations, resulting in decreases in the firing rate of this neuron of $11 \%, 13 \%$, and $46 \%$, respectively, compared to the firing rate pre-drug. For this and all of the following figures: unit activity (EVENTS) is represented on the $y$-axis; time in seconds on the $x$-axis; the histogram bin width equals $720 \mathrm{msec}$. are shown in Figures 3 and 4. Two other spontaneously active neurons, Type $C$, fired with bursts of 3-5 spikes every 2-5 sec. This type of neuron was not tested for effects of drug superfusion.

\section{Drug Concentrations}

The concentrations of glutamate, GABA, and bicuculline used in this study were determined in initial experiments where different drug concentrations were superfused while recording single-unit or multi-unit activity. Data from one experiment where different GABA concentrations were superfused are illustrated in Figure 2. GABA effects were evaluated after superfusion of $50 \mu \mathrm{M}$ glutamate (Fig. 2A). Subsequent superfusion of $3 \mathrm{mM}$ GABA (Fig. 2B) resulted in an $11 \%$ decrease in activity when the $30 \mathrm{sec}$ pre-GABA baseline period was compared to the $90 \mathrm{sec}$ period after GABA superfusion. Superfusion of $15 \mathrm{mM}$ GABA resulted in a $13 \%$ decrease in activity (Fig. 2C), while superfusion of $30 \mathrm{mM}$ GABA (Fig. 2D) decreased activity by $46 \%$ compared to preGABA baseline. The concentration of bicuculline used in this study was similarly determined in initial experiments evaluating drug effects on single- and multi-unit activity. In each case, superfusion of $1 \mathrm{mM}$ bicuculline did not change the spontaneous firing, while subsequent superfusion of $2 \mathrm{mM}$ bicuculline resulted in increased neuronal activity.

\section{Effects of Glutamate and GABA Superfusions}

The effects of superfusion of L-glutamate (50 $\mu \mathrm{M})$, GABA ( $3 \mathrm{mM}$ or $30 \mathrm{mM}$ ), or the GABA receptor antagonist bicuculline $(2 \mathrm{mM})$ were evaluated on 22 neurons. Multiple and/or repeated superfusions were made on 11 neurons. The number of individual neurons that were tested for drug superfusion effects and the number of neurons that increased or decreased their basal firing rates by at least $20 \%$, or were not affected, are shown in Table 1.

The effects of glutamate were evaluated on ten neurons. Glutamate superfusion increased the firing rates of five neurons. Figure $2 \mathrm{~A}$ shows the effect of glutamate superfusion on a Type A neuron. The baseline firing rate of this neuron was $9.0 \mathrm{~Hz}$. The mean firing rate for the $60 \mathrm{sec}$ period after superfusion of 
TABLE 1

SUMMARY OF DRUG SUPERFUSION EFFECTS

\begin{tabular}{lccc}
\hline & \multicolumn{3}{c}{ Effect } \\
\cline { 2 - 4 } & + & - & 0 \\
\hline Glutamate $(n=10)$ & 5 & 3 & 2 \\
GABA $(n=12)$ & 0 & 12 & 0 \\
Bicuculline $(n=8)$ & 8 & 0 & 0 \\
\hline
\end{tabular}

$\mathrm{n} \quad=$ number of tested neurons

$+\quad=$ increase in spontaneous activity

- $\quad=$ decrease in spontaneous activity

$0=$ no change in spontaneous activity
$50 \mu \mathrm{M}$ glutamate was $29.0 \mathrm{~Hz}$, an increase of $322 \%$. The firing rate returned to near baseline level by 100 sec after drug superfusion. When the data were analyzed for all neurons displaying an increase in activity after glutamate superfusion, it was found that the latency to these increases varied from 1-35 sec $($ mean $=14.2 \mathrm{sec})$ and the magnitude of the increase varied from $165-379 \%$ of the mean baseline activity. Increases in activity after glutamate superfusion were observed on both Type A $(n=3)$ and Type B $(n=2)$ neurons.

Glutamate administration resulted in a decrease in activity for three neurons, even though in two cases there were increases in the activity of neurons

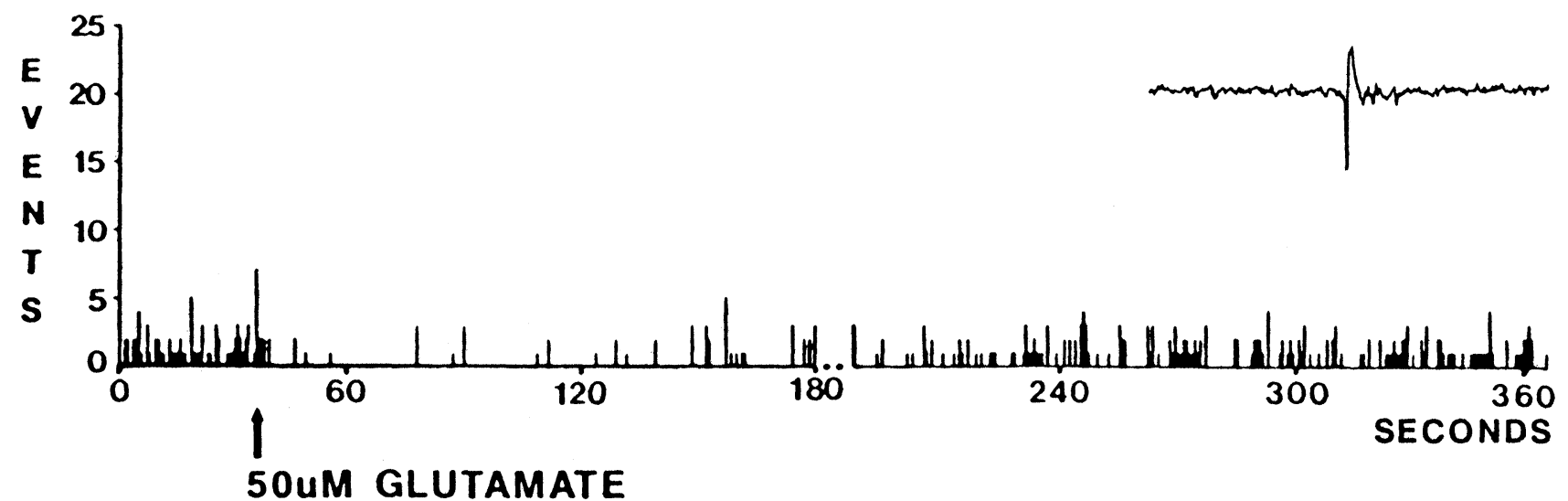

Fig. 3: Histogram of the firing rate of an intraocular graft Type B neuron (see text) which exhibited a reduction in spontaneous activity after glutamate $(50 \mu \mathrm{M}$ ) superfusion (arrow). For this and all of the following figures the spike waveform generated by the neuron under study is shown in the inset (sweep length equals $20 \mathrm{msec}$ ).

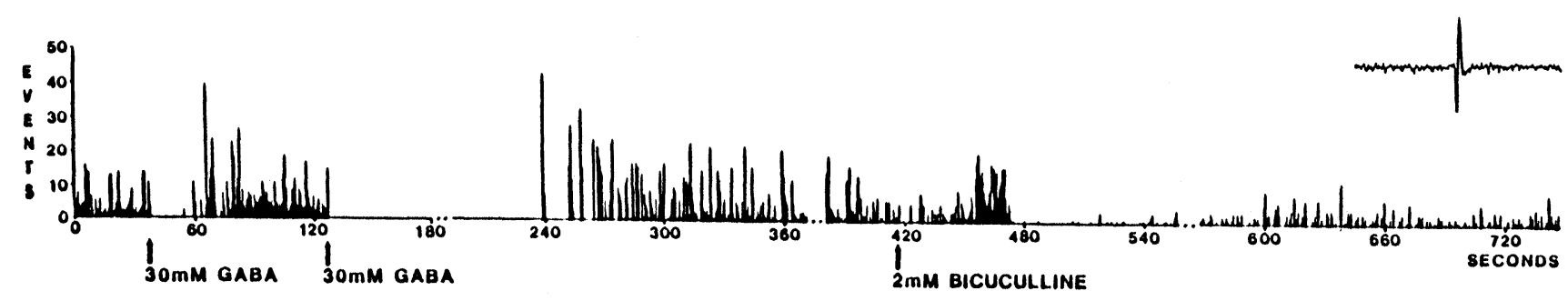

Fig. 4: The effects of repeated applications (arrows) of GABA ( $30 \mathrm{mM}$ ), and the response to bicuculline (2 mM) on a Type B neuron (see text). The first superfusion of GABA resulted in a cessation of spontaneous activity lasting $15 \mathrm{sec}$. A second superfusion of GABA produced a silent period lasting $110 \mathrm{sec}$. Superfusion of bicuculline resulted in an initial increase, followed by a decrease in activity. Note slow recovery of spontaneous activity following the inhibitory effect of bicuculline. 
recorded below the discriminator window. An example of this effect on a Type B neuron is illustrated in Figure 3. The mean firing rate of this unit decreased from $2.4 \mathrm{~Hz}$ to $0.6 \mathrm{~Hz}(75 \%)$ over a $60 \mathrm{sec}$ period after superfusion of $50 \mu \mathrm{M}$ glutamate. The onset latency of this decrease was $8 \mathrm{sec}$. The mean firing rate for the period $30 \mathrm{sec}$ after the onset of effect was $1.1 \mathrm{~Hz}$, a decrease of $54 \%$. Data from the three neurons that reduced their firing rate after glutamate showed that the latency of these effects varied from 8-18 sec (mean $=12.7 \mathrm{sec}$ ) while the magnitude of the decrease varied from $37-96 \%$ of the baseline activity. All of the units which decreased their firing rate after glutamate superfusion were Type B neurons. Glutamate superfusion had no effect on the firing rate of two other Type B neurons.

In contrast to the mixed effects of glutamate, addition of 3-30 mM GABA to the recording chamber reduced the firing rate of all 12 neurons tested (Table 1). Figure 4 illustrates the effects of consecutive superfusions of GABA on a Type B neuron that had a spontaneous firing rate of $7.4 \mathrm{~Hz}$ during the $30-\mathrm{sec}$ pre-drug control interval. After the first GABA superfusion $(30 \mathrm{mM})$, this neuron stopped firing for $15 \mathrm{sec}$. The neuron then resumed firing, initially in short bursts, then at a near-baseline level, at which time GABA was again administered. The second superfusion of GABA resulted in a longer cessation of activity lasting $110 \mathrm{sec}$, followed by a longer period of bursting activity before the neuron resumed firing at near-baseline level.

The effects of GABA superfusion on spontaneous activity were tested on four Type $A$ and eight Type $B$ neurons. The latency of effects observed on this group of neurons varied from $1-27 \mathrm{sec}$ (mean $=9.2 \mathrm{sec}$ ). The magnitude of the inhibitory effects of GABA, calculated as above, ranged from $20-98 \%$. Silent periods similar to those seen in Figures 4 and 5, and lasting at least $10 \mathrm{sec}$, were seen in $9 / 12$ tested neurons after GABA superfusion.

The GABA receptor antagonist bicuculline increased the firing rate of all eight neurons tested. Two different types of effects were observed following bicuculline administration. In four cases, the excitatory effect of bicuculline lasted less than $60 \mathrm{sec}$ and was followed by a decrease in unit activity. Figure 4 illustrates an example of this type of bicuculline effect. In four other cases, the effect of bicuculline was long- lasting and included the appearance of bursts of unit firing superimposed on a neuron's regular pattern of activity. An example of this type of effect is shown in Figure 5. This effect occurred following the administration of GABA ( $30 \mathrm{mM})$ which produced a long-lasting $(408 \mathrm{sec})$ inhibition of the cell's spontaneous discharge. Superfusion of bicuculline (2 $\mathrm{mM}$ ) brought about a return of the cell's discharge to a level $255 \%$ above the pre-GABA control level. After this initial burst of activity, which lasted nearly 200 sec, the activity pattern of the cell consisted of periodic bursts of spikes superimposed on a background activity level similar to that observed during the pre-drug control period. After a second application of GABA, again there was a complete cessation of the cell's discharge lasting $184 \mathrm{sec}$. Recovery from this second GABA administration consisted of an initial return of the bursting activity followed by a later return to the cell's pre-drug discharge pattern.

\section{Electrode Depth and Superfusion Effect}

An attempt was made to determine if the variations in latency and magnitude of effects described above were due to differences in the depth of the recording electrode below the graft surface. For the 10 neurons where glutamate was superfused, the electrode depth ranged from 159-634 $\mu \mathrm{m}$ (mean $=399 \mu \mathrm{m})$. No significant correlation was found when electrode depth was compared to the type of glutamate effect (i.e., increase or decrease of spontaneous firing rate), the latency to the glutamate effect, or the magnitude of effect. The electrode depths for the 12 neurons studied with GABA ranged from 94-624 $\mu \mathrm{m}$ (mean = $367 \mu \mathrm{m}$ ). Again no significant correlation was found between the electrode depth and either the latency or magnitude of the GABA effect.

\section{DISCUSSION}

The technique of drug administration used in this study was chosen as an initial means of assessing the feasibility of studying glutamate and GABA effects on intraocular graft neurons. We were aware of potential problems of interpretation using this technique. Changes in the temperature of the chamber fluid surrounding the graft might change the spontaneous 
firing rate of a neuron independent of the effect of superfused drugs. Furthermore, displacement of fluid by the drug might move the graft, thereby decreasing the amplitude of the recorded unit below the discriminator window. Initial experiments indicated that these were not serious problems. First, the monitored temperature of the solution did not noticeably change after drug superfusion. Further, in some instances drug superfusion did not have an effect (Table 1). Therefore it is unlikely that changes in fluid temperature produced spurious results. As for the possibility of pressure changes reducing the amplitude of recorded neurons, the observed amplitudes of action potentials did not change after drug superfusion. Similarly, after GABA-induced silent periods, action potentials eventually resumed which were the same amplitude as those observed pre-drug. Therefore the drug superfusion technique was determined to be appropriate for this initial study of glutamate and GABA effects on intraocular graft neurons.

Many neurons in intraocular spinal cord grafts were found which displayed repeated, often very regular rates of discharge. It is thought that this activity is generated within the graft itself, rather than as the result of innervation from the iris $/ 15,29 /$. In this regard, spontaneously active neurons have also been observed in cultured spinal cord neurons in vitro $/ 21,31,32 /$. In the present study we used this activity to identify neurons prior to superfusion of glutamate, GABA, and the GABA antagonist bicuculline.

Superfusion of the graft with glutamate had an excitatory effect on five of ten neurons tested. The increase in firing rate is in accordance with studies of spinal cord neurons, where glutamate was iontophoresed $/ 8,10,37 /$ or applied to a spinal cord slice preparation $/ 22,33 /$. With three of ten tested neurons, superfusion of glutamate resulted in decreases in spontaneous firing rate. It is unlikely that this effect is due to a direct inhibitory action of glutamate, although such an effect has been demonstrated previously for cerebellar interneurons /38/ studied in vitro. Rather, the decrease in firing rate may be due to glutamate activation of GABA-ergic interneurons which influence
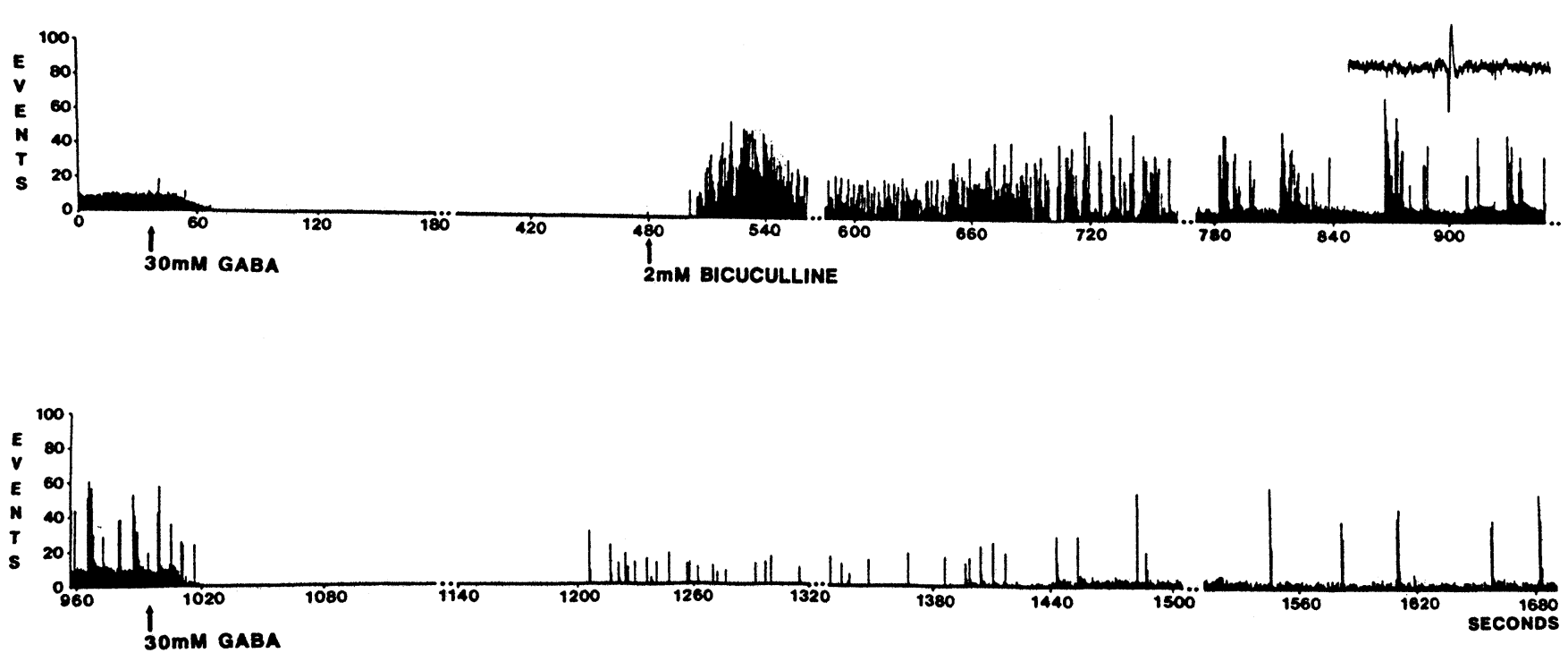

Fig. 5: Effects of GABA and bicuculline superfusions (arrows) on a Type A neuron (see text). The first superfusion of GABA (30 mM) resulted in a long-lasting inhibition of the cell's spontaneous activity. Following bicuculline $(2 \mathrm{mM})$ administra-tion there was an initial increase in the cell's discharge rate. Note periodic bursts of activity that were not present during the pre-drug control period at the beginning of the histogram. A second applications of GABA produced a total inhibition of the cell's discharge. Note recovery of burst discharges prior to the return of the cell's pre-drug activity level. 
the firing rate of the neuron being studied. This explanation has previously been used to explain the decrease in activity which is sometimes seen subsequent to glutamate-induced neuronal excitation $/ 26 /$. Our results of a widespread effect of GABA on graft neurons suggests that this interpretation may apply to spinal cord grafts.

The decrease in unit firing after glutamate superfusion may also be due to rapid overdepolarization of the membrane of the neuron being studied resulting in conduction block $/ 23 /$. Since a dose-response profile of glutamate effects was not carried out, it is not known if any of the three neurons which reduced their spontaneous activity after glutamate superfusion would have increased their spontaneous rate after lower concentrations of glutamate. The concentrations of glutamate used in this study are comparable to those used previously in studies of glutamate administration to the spinal cord slice $/ 22,33$ / where decreases in activity were not seen.

Superfusion of GABA resulted in decreases in the firing rate of all 12 spinal cord graft neurons. This effect could be reversed by bicuculline. Similar results were obtained when recording from spinal cord neurons $/ 8 /$ and from in vitro studies of cultured spinal cord neurons $/ 4,35 /$. These results indicate that GABA functions in intraocular grafts, as in the spinal cord $/ 8,24 /$, to inhibit neuronal transmission.

Neurons in the present study were grouped into three classes according to their pattern of spontaneous activity. This has not been done in previous studies in which responses of intraocular spinal cord graft neurons were studied $/ 14,15,18,29 /$. In the present study only Type B neurons, which had somewhat irregular rates of spontaneous activity, either were unaffected or decreased their firing rate after glutamate superfusion. It is not known whether different neurons types described in the present study represent neurons with different morphological characteristics. We have previously shown that graft neurons vary considerably in size and dendritic organization $/ 6 /$. Further studies of neuronal responses to similar superfusions combined with intracellular marking techniques could help determine if there is a relationship between neuronal morphology and the effects described in the present study.

The variability in the latency and magnitude of effects of GABA superfusions and the independence of these parameters on the depth of the recording electrode, suggest that neurons in spinal cord grafts are affected in different ways, and to different degrees, by GABA. The superfusion technique used in this study precluded any conclusions being made regarding the pre- or post-synaptic action of GABA. Future studies where GABA and GABA receptor antagonists are administered iontophoretically while recording neuronal activity are needed to resolve this issue.

This initial study of glutamate and GABA sensitivity was carried out on grafts of immature rat spinal cord transplanted to the anterior eye chamber of adult rat hosts. An important question regarding the results concerns changes in drug sensitivity when neurons are in the presence of tissue that can provide afferent input and/or an efferent target. A major target of spinal cord projection neurons is the mesencephalon /40/. Presently we are studying the effects of cografting fetal mesencephalon with spinal cord neurons to determine the effects of this target tissue on the physiology and pharmacology of transplanted spinal cord neurons.

In conclusion, the results of the present study have shown that spinal cord graft neurons respond to glutamate and GABA. It has previously been shown that neurons in similar grafts display morphological and organizational characteristics similar to those found in situ $/ 6 /$, and that graft neurons contain several neuropeptides present in the in situ spinal cord $/ 16 /$. Further, intraocular graft neurons respond to norepinephrine /14/ and serotonin /18/. Together, these data suggest that the intraocular spinal cord graft is a useful model for the study of the physiology and pharmacology of simple neural networks in the developing and mature spinal cord. This model may be useful for the study of phenomena such as denervation supersensitivity, the influence and interaction of multiple transmitter systems on single neurons, and pharmacological changes that occur during the development of ascending and descending spinal pathways.

\section{ACKNOWLEDGEMENTS}

The authors would like to thank Drs. R.A. Davidoff and J. Vicedomini for their helpful critiques of an earlier version of this manuscript, Elisabet Jakobsson 
for technical assistance, and Theresa Whittingham for secretarial assistance. This work was supported by NIH Grant NS19509 to RPY and by The Miami Project to Cure Paralysis.

\section{REFERENCES}

1. Armstrong-James M, Millar J. Carbon fibre microelectrodes. J Neurosci Meth 1979; 1:279-287.

2. Barber RP, Vaughan JE, Saito K, McLaughlin B, Roberts E. GABAergic terminals are presynaptic to primary afferent terminals in the substantia gelatinosa of the spinal cord. Brain Res 1978; 141:35-55.

3. Barber RP, Vaughan JE, Roberts E. The cytoarchitecture of GABAergic neurons in rat spinal cord. Brain Res 1982; 238:305-328.

4. Barker JL. Electrophysiological actions of GABA and diazepam in cultured CNS neurons. In RF Squires (Ed.), GABA and benzodiazepine receptors, Vol. I, Chap. 3. Boca Raton: CRC Press, 1988, pp. 59-73.

5. Berger SJ, Carter JG, Lowry OH. The distribution of glycine, GABA, glutamate and aspartate in rabbit spinal cord, cerebellum and hippocampus. J Neurochem 1977; 28:149-158.

6. Broton, JG, Yezierski RP, Seiger Å. Intraocular grafts of fetal rat spinal cord: A Golgi study of neuronal morphology and organization. Exp Neurol 1990; 108: $122-129$.

7. Broton, JG, Yezierski RP, Seiger Å. Effects of GABA on neurons in intraocular spinal cord grafts. Soc Neurosci Abst 1989; 15:1242.

8. Curtis DR, Johnston GAR. Amino acid transmitters in the mammalian central nervous system. Ergebn Physiol 1974; 59:97-188.

9. Davidoff RA, Graham Jr, RP, Shank RP, Werman R, Aprison MH. Changes in amino acid concentrations associated with loss of spinal interneurons. J Neurochem 1967; 14:1025-1031.

10. Davies J, Watkins JC. Selective antagonism of amino acid induced and synaptic excitation in the cat spinal cord. J Physiol (Lond) 1979; 297:621-635.

11. Duggan AW, Johnston GAR. Glutamate and related amino acids in cat spinal roots, dorsal root ganglia and peripheral nerves. J Neurochem 1970; 17:1205-1208.

12. Graham Jr, LT, Shank RP, Werman R, Aprison MH. Distribution of some synaptic transmitter suspects in cat spinal cord: Glutamic acid, aspartic acid, gammaaminobutyric acid, glycine, and glutamine. J Neurochem 1967; 14:465-472.

13. Greenamyre JT, Young AB, Penney, Jr JB. Quantitative autoradiographic distribution of $\mathrm{L}\left({ }^{3} \mathrm{H}\right)$ glutamate-binding sites in rát central nervous system. J Neurosci 1984; 4:2133-2144.

14. Henschen A, Goldstein M, Palmer MR. Evidence for functional contact between cografted locus coeruleus and spinal cord in oculo: Electrophysiological studies. Brain Res 1988; 474:66-74.

15. Henschen A, Hoffer B, Olson L. Spinal cord grafts in oculo; Survival, growth, histological organization, and electrophysiological characteristics. Exp Brain Res 1985; 60:38-47.

16. Henschen A, Hökfelt T, Elde R, Fahrenkrug J, Frey P, Terenius L, Olson L. Expression of eight neuropeptides in intraocular spinal cord grafts: Organotypical and disturbed patterns as evidenced by immunohistochemistry. Neuroscience 1988; 26:193-213.

17. Henschen A, Kessler J, Seiger $\AA$, Olson L. Enkephalin and capsaisin-resistant substance P-like immunoreactivities in intra-ocular grafts of different spinal cord areas. Acta Physiol Scand 1986; 128:175-185.

18. Henschen A, Palmer MR, Olson L. Raphe dorsalis spinal cord cografts in oculo: Electrophysiological evidence for an excitatory serotonergic innervation of transplanted spinal neurons. Brain Res Bull 1986; 17:801-808.

19. Henschen A, Zerbe G, Nadzan AM, McKelvy JF, Olson L, Hoffer B. Thyrotropin releasing hormone augments growth of spinal cord transplants in oculo. Exp Neurol 1988; 102:125-129.

20. Hoffer B, Seiger $\AA$, Freedman R, Olson L, Taylor D. Electrophysiology and cytology of hippocampal formation transplants in the anterior chamber of the eye. II Cholinergic mechanisms. Brain Res 1977; 119: 107-132.

21. Jackson MB, Lecar H, Brenneman DR, Fitzgerald S, Nelson PG. Electrical development in spinal cord cell culture. J Neurosci 1982; 2:1052-1061.

22. King AE, Thompson SWN, Urban L, Woolf CJ. An intracellular analysis of amino acid induced excitations of deep dorsal horn neurons in the rat spinal cord slice. Neurosci Letts 1988; 89:286-292.

23. Krnjevic K. Microiontophoretic studies on cortical neurones. Int Rev Neurobiol 1964; 7:41-98.

24. Levy RA. The role of GABA in primary afferent depolarization. Prog Neurobiol 1977; 9:211-267.

25. Magoul R, Onteniente B, Geffard M, Calas A. Anatomical distribution and ultrastructural organization of the GABAergic system in the rat spinal cord. An immunocytochemical study using anti-GABA antibodies. Neuroscience 1987; 20:1001-1009.

26. Mayer ML, Westbrook GL. The physiology of excitatory amino acids in the vertebrate central nervous system. Prog Neurobiol 1987; 28:197-276.

27. McLaughlin BJ, Barker R, Saito K, Wu JY. Immunocytochemical localization of glutamate decarboxylase in the rat spinal cord. J Comp Neurol 1975; 164:305-322.

28. Miller KE, Clements JR, Larson AA, Beitz AJ. Organization of glutamate-like immunoreactivity in the rat superficial dorsal horn: Light and electron microscope observations. Synapse 1988; 2:28-36.

29. Olson L, Björklund H, Hoffer B, Palmer MR, Seiger $\AA$. Spinal cord grafts: An intraocular approach to enigmas 
of nerve growth regulation. Brain Res Bull 1982; 9:519537.

30. Olson L, Seiger $\AA$, Strömberg I. Intraocular transplantation in rodents. A detailed account of the procedure and examples of its use in neurobiology with special reference to brain tissue grafting. In S Fedoroff, L Hertz (Eds.), Advances in Cellular Neurobiology, 4. New York: Academic Press, 19?, pp. 407-442.

31. Peacock JH, Nelson PG. Goldstone MW Electrophysiologic study of cultured neurons dissociated from spinal cords and dorsal root ganglia of fetal mice. Dev Biol 1973; 30:137-152.

32. Ransom BR, Neale E, Henkart M, Bullock PN, Nelson PG. Mouse spinal cord cells in culture. I. Morphology and intrinsic neuronal electrophysiological properties. J Neurophysiol 1977; 40:1132-1150.

33. Schneider SP, Perl ER. Selective excitation of neurons in the mammalian spinal dorsal horn by aspartate and glutamate in vitro: Correlation with location and excitatory input. Brain Res 1985; 360:339-343.

34. Seiger $\AA$, Holets VR, Miller KE. Intraocular spinal cord transplantation: Model for studies of growth differen- tiation and synaptic organization. Int Pediatr 1988; 3:8185.

35. Ticku M, Mehta A, LeHoullier P. Spinal cord cultured neurons: An in vitro model to study GABA synaptic pharmacology. In G Biggio, E Costa (Eds.), Chloride channels and their modulation by neurotransmitters and drugs. New York: Raven Press, 1988, pp. 151-159.

36. Thomas WE. Studies of neurotransmitter chemistry of central nervous system neurons in primary tissue culture. Life Sci 1986; 38:297-308.

37. Watkins JC, Evans RH. Excitatory amino acid transmitters. Ann Rev Pharmacol Toxicol 1981; 21:165-204.

38. Yamamoto $\mathrm{C}$, Yamashita $\mathrm{H}$, Chujo $\mathrm{T}$. Inhibition and excitation by glutamic acid on cerebellar interneurons. Jap J Physiol 1977; 27:225-234.

39. Yellin $H$. Survival and possible trophic function of neonatal spinal cord grafts in the anterior chamber of the eye. Exp Neurol 1976; 51:579-592.

40. Yezierski RP. The spinomesencephalic tract: Projections from the lumbosacral spinal cord of the rat, cat, and monkey. J Comp Neurol 1988; 267:131-146. 

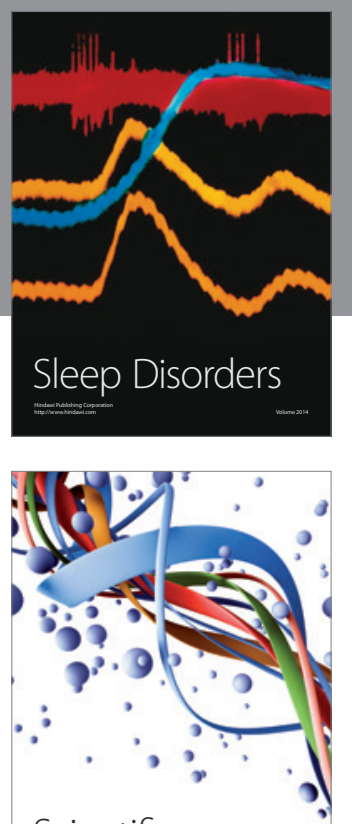

Scientifica
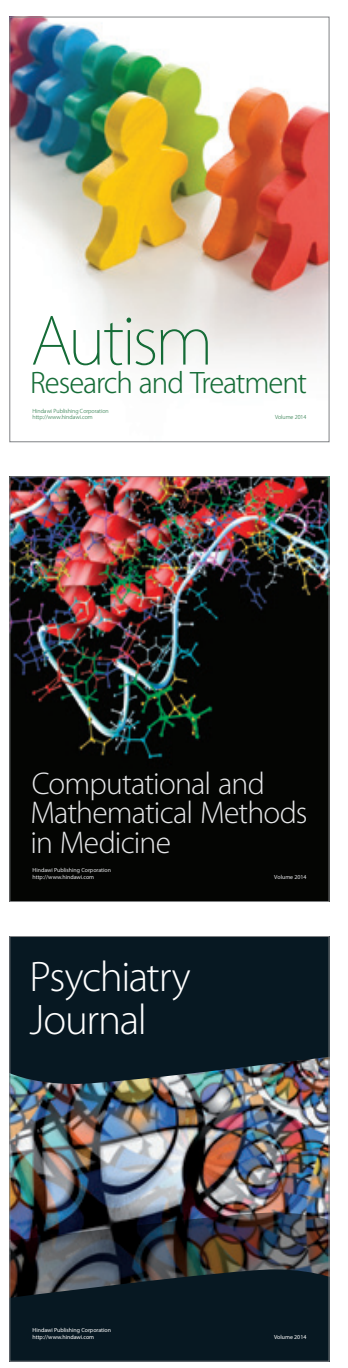
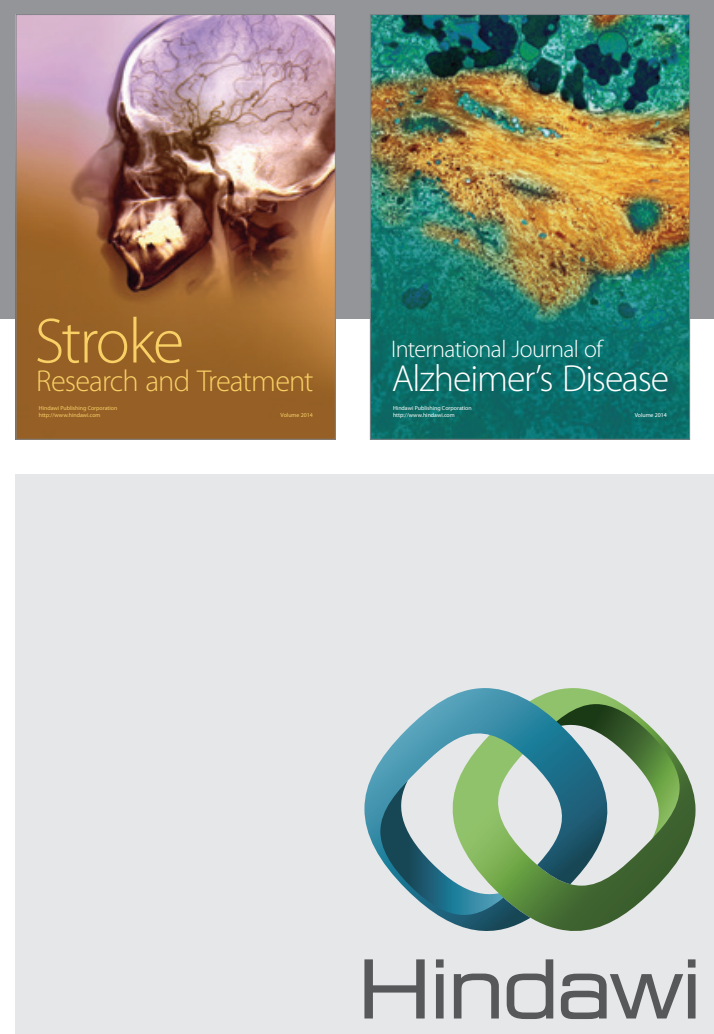

Submit your manuscripts at

http://www.hindawi.com
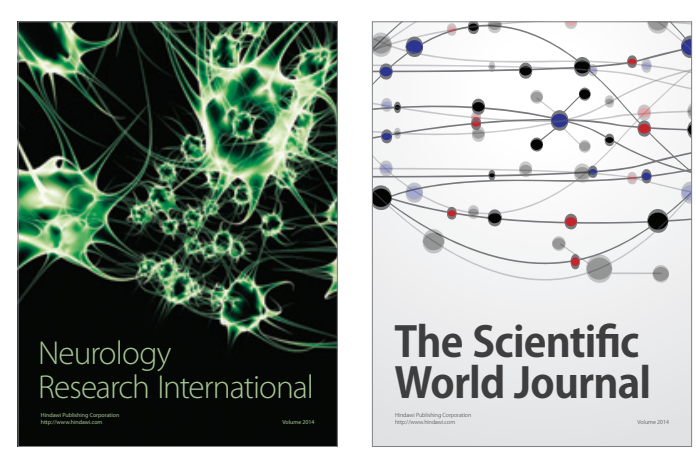

The Scientific World Journal

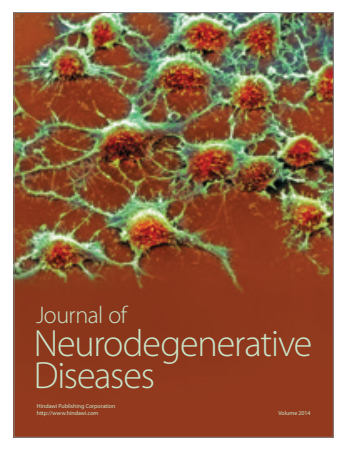

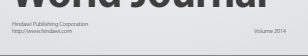

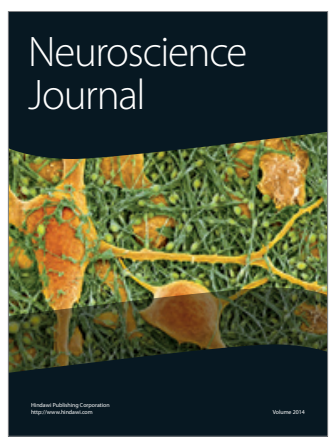

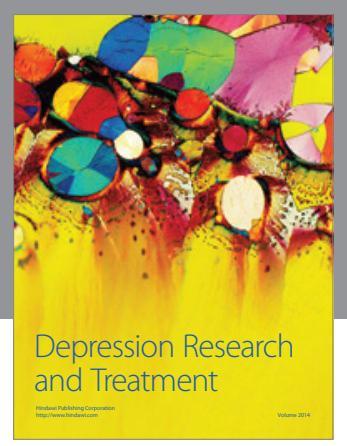
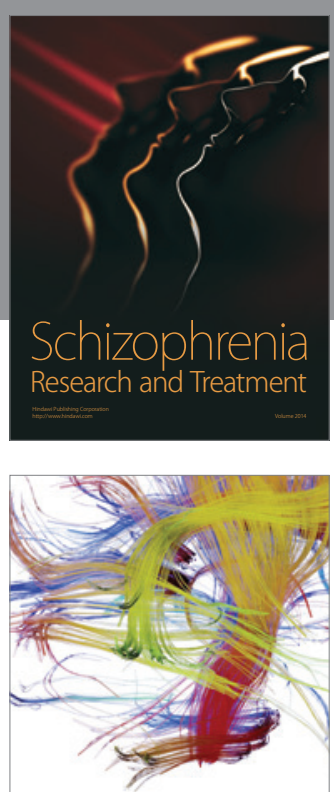

Brain Science

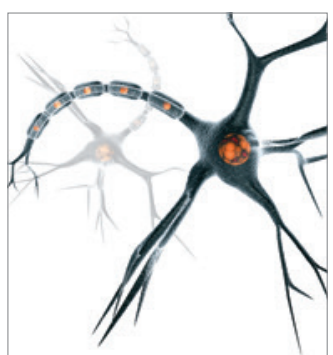

Neural Plasticity
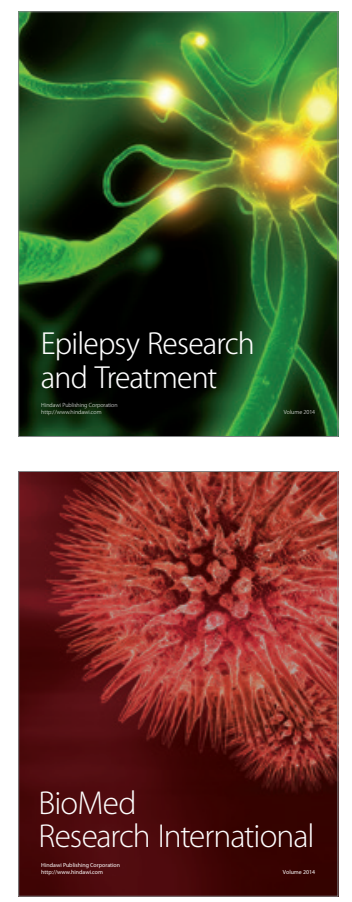

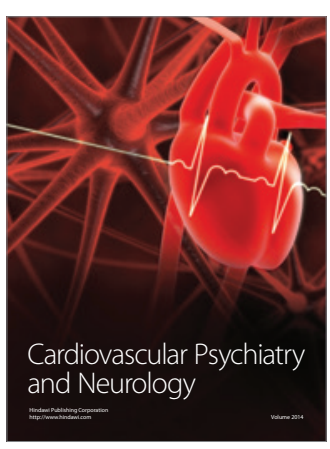

Parkinson's

Disease
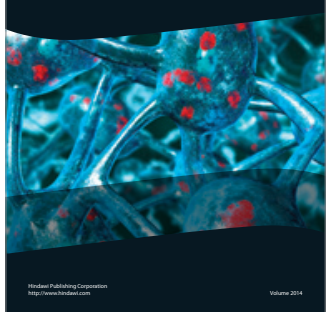